\title{
DIVERSIDADE SEXUAL HUMANA: NOTAS PARA A DISCUSSÃO NO ÂMBITO DA PSICOLOGIA E DOS DIREITOS HUMANOS
}

\author{
Maria Juracy Filgueiras Toneli*
}

\section{RESUMO}

A proposta do presente trabalho é a de colocar em discussão a noção de diversidade sexual no cenário contemporâneo enredado pelos processos de medicalização e psicopatologização. Analisam-se as contribuições da Psicologia nesse âmbito, entendendo que se trata de um campo constituído por práticas discursivas diversas imbricadas em jogos de forças que se objetivam, por exemplo, nos códigos internacionais de doenças. A noção de direitos sexuais, ainda polêmica, inclui-se nessa cena dinâmica na qual os sujeitos se vêem às voltas com a "verdade" do (seu) sexo como um genuíno paradoxo, uma vez que o sexo que revela é o mesmo que assujeita.

Palavras-chave: sexualidade; diversidade; relaçôes de poder; direitos sexuais.

\section{Abstract}

SEXUAL HUMAN DIVERSITY: NOTES FOR A DISCUSSION IN THE PSYCHOLOGICAL AND HUMAN RIGHTS SCENE

The proposal of the present work is to discuss the notion of sexual diversity in the contemporary scene tangled with medicalization and psychologization processes. It analyzes the contributions of Psychology in this scope, understanding that this is a field consisting of diverse discursive practices in power relations that objectify, as is the case, for example, of the international codes of illnesses. The notion of sexual rights, still controversial, is included in this dynamic scene in which citizens seem to occupy themselves with the "truth" of (their) sex as a genuine paradox, in a time in which sex can disclose as well as subject.

Keywords: sexuality; diversity; power relations; sexual rights.

* Departamento de Psicologia da Universidade Federal de Santa Catarina (UFSC). 
"Mas, portanto, a diferença sexual permanece a interpretar, a decifrar, a decodificar, a ler e não a ver. Legível, por conseguinte invisível, objeto de testemunho e não de prova - e ao mesmo tempo problemática, móvel, não assegurada, ela passa, ela é de passagem".

(Derrida, 1994: 74-75; tradução nossa)

"Tem-se uma sexualidade desde o século XVIII, o sexo desde o XIX. Antes, tinha-se, sem dúvida, a carne".

(Foucault, [1977] 1994: 313; tradução nossa)

Diversidade Sexual Humana era o título de uma mesa-redonda para a qual fui convidada em um encontro da área da saúde realizado na Universidade Federal de Santa Catarina em $2005^{1}$, que tinha como intenção debater sobre a diversidade sexual, a relação com o corpo e os preconceitos sexuais. Um ano depois, em agosto de 2006, em outra mesa-redonda com o título "Erotismo, Sexualidade e Preconceitos" ${ }^{2}$, novamente me deparei com a tarefa de debater acerca desta temática, ocasião na qual desenvolvi um pouco mais as reflexões que havia apresentado anteriormente.

O presente texto resulta dessas duas apresentações. Com o intuito de não me restringir a uma repetição dos debates já elaborados sobre essas temáticas, partirei do enunciado da diversidade sexual humana para tentar desenvolver algumas questões que considero problemáticas no que diz respeito à interface Biomedicina/ Psicologia desde o final do século XIX. As dificuldades que as diferenciações entre sexo e gênero ainda enfrentam também serão assinaladas. Finalizo com algumas questôes que deixo para reflexão e discussão.

\section{DiVERSIDADE SEXUAL HUMANA: AINDA UMA QUESTÃO POLÊMICA}

O enunciado da diversidade sexual humana é hoje possível em função dos deslocamentos epistemológicos, bem como de mudanças sociopolíticas e tecnológicas ocorridas a partir do século XVIII. Sexo e sexualidade são termos que se constituem em objetos de pesquisa e discussão teórica em diversas áreas do conhecimento nesse início do século XXI. Uma estratégia historicizante torna-se fundamental, portanto, para que se possa compreender como determinadas áreas monopolizaram essa discussão.

Acompanhando as reflexões de Luiz Fernando Duarte (2004), sugere-se que a emergência do interesse específico pelo tema pode ser associada a três outros 
processos que marcam a inflexão moderna da cultura ocidental: 1) a separação da sexualidade como ente de razão moderno com relação à família, à reprodução, à religião, à moralidade; 2) a emergência das ideologias portadoras do "fisicalismo" (biomédicas universalizantes) e do "simbolismo" (psicossociológicas singularizantes); 3) a hegemonia dos valores da interioridade (psicologização) e do prazer (hedonismo).

Além disso, é preciso relembrar que, até o século XVIII, o modelo do sexo único era dominante. Thomas Laqueur (1992) mostra com propriedade como, decorrente de uma pluricausalidade na qual se incluem o mecanicismo, o empiricismo, a síntese newtoniana e a instituição das dicotomias características do pensamento moderno e as novas demandas do contexto político marcado pela divisão entre esfera pública e privada, o corpo passou a se constituir no cerne da sociedade civil. A diferenciação entre homens e mulheres torna-se fundamental e com ela a superação do modelo do sexo único. O que o historiador argumenta é que os avanços científicos, como os da anatomia do Renascimento e a classificação dos seres vivos - formulada por Lineu - que tem como ordenador a reprodução, não são suficientes para explicar tal ordem de transformação. Para ele, há uma imbricação de modos discursivos e a possibilidade de arranjos diferentes, embora seja possível localizar alguns vetores que se tornam mais proeminentes (como os mencionados), que fizeram com que o corpo e suas diferenciações fossem concebidos como entidades naturais.

Nessa mesma época, a obra do Marquês de Sade mostrou, pela primeira vez, a sexualidade como um instituto próprio da condição humana (independente da moral e da religião e capaz de determinar a carreira dos sujeitos sociais). Finalmente, também no século XVIII, foram constituídas as primeiras formulações sistemáticas de uma economia política, de uma teoria da reprodução coletiva da espécie humana. Nesses quatro acontecimentos do século XVIII, apenas um (o caso de Sade) mantém uma ênfase não-reprodutiva, hedonista (Duarte, 2004).

Ao longo do século XIX, o desenvolvimento da pesquisa biológica continua marcado pela fisiologia da reprodução. Por outro lado, a retomada da diferença mostra-se, sobretudo, na tematização da condição normal da sexualidade e de sua degeneração. A Psicologia surge aqui, direcionando-se para a psicofísica e para pesquisas sobre as reações dos sistemas sensoriais - incluindo a excitação sexual e as chamadas "respostas sexuais". O que se pode observar de diferenciação com relação ao século anterior é uma maior separação entre a sexualidade e a reprodução. No entanto, por outra via, há uma aproximação maior da sexualidade com a moralidade. Nem mesmo a Psicanálise escapa a esta aproximação, uma vez que, embora tenha promovido rupturas com o pensamento hegemônico que via as 
crianças como assexuadas e tenha redefinido a própria noção de sexualidade colocando-a em posição central no desenvolvimento do psiquismo, a escola freudiana manteve-se apegada à moralidade vitoriana, inclusive no que diz respeito à orientação sexual.

Já no século XX, pode-se constatar o jogo de forças entre os saberes "psicológicos", os saberes "sociais" e os saberes "médicos". É na obra de Michel Foucault ([1976] 1997, [1977] 1994) que mais claramente se pode encontrar a demonstração da construção social da sexualidade e de sua emergência como instância de verdade do sujeito, graças aos citados saberes "disciplinadores". O sexo foi colocado em discurso, segundo Foucault ([1976] 1997), a partir do moralismo burguês do século XIX, alçando o estatuto de poder explicitar a verdade do sujeito - de seu interior - e de sua ruína, quando fosse o caso. Instaura-se, então, um processo de sexualização generalizada que tem nas crianças um de seus principais focos e nas famílias um lócus de observação, reflexão e controle sexual de seus membros (Duarte, 2004).

A partir da década de 70 do século XX, tem-se um crescente interesse intelectual sobre a sexualidade em seus vários aspectos e dimensões, marcado por tendências teóricas distintas. De acordo com Maria Andréa Loyola (1998), a delimitação da sexualidade varia de acordo com esquemas conceituais utilizados e em função dos ângulos a partir dos quais a problemática é abordada. Por vezes ela é associada intrinsecamente à família e/ou às redes de parentesco, por outras, é pensada como constitutiva da subjetividade e/ou da identidade individual e social. Por outras ainda, é concebida como representação, desejo ou, simplesmente, atividade ou comportamento (Piscitelli, Gregori \& Carrara, 2004). Todas essas possibilidades atravessam o campo da Psicologia.

Deve-se destacar nesse cenário, também, a emergência dos movimentos sociais organizados - especialmente os de minorias como o feminista e o homossexual -, a entrada massiva das mulheres no mercado de trabalho assalariado acompanhada de sua crescente escolarização - e, na década de 1960, o advento da pílula anticoncepcional, que favoreceu sobremaneira a separação entre sexualidade e reprodução.

No campo da Psicologia, a influência dos modelos "fisicalistas" (universalista, redutor à natureza, próximo do essencialismo biomédico), por um lado, e dos modelos "românticos" (simbolizantes e psicossociológicos), por outro, continuou marcando a produção científica que se expressa ora em busca de uma perspectiva universalizante generalista, ora em busca das especificidades dos processos de singularização. Ou seja, a sexualidade e suas expressões são tratadas de uma forma ou outra dependendo da tradição teórica que ilumina os trabalhos. 
A influência biomédica pode ser identificada até os dias atuais quando o próprio Conselho Federal de Psicologia, em resolução de 1999, teve o cuidado de alertar os psicólogos brasileiros sobre o fato de que a homossexualidade "não constitui doença, nem distúrbio e nem perversão", que "há, na sociedade, uma inquietação em torno de práticas sexuais desviantes da norma estabelecida sócio-culturalmente" e "a Psicologia pode e deve contribuir com seu conhecimento para o esclarecimento sobre as questôes da sexualidade, permitindo a superação de preconceitos e discriminaçôes" (Conselho Federal de Psicologia, 1999: s/p).

No DSM-IV (American Psychiatric Association, 1995), as anomalias referentes à sexualidade mantêm-se presentes, a despeito da retirada do termo "homossexualismo" em 1971. Pode-se considerar como um eufemismo o termo classificatório agora utilizado: Transtorno de identidade de gênero. Observa-se, aqui, a heteronormatividade (Butler, 2003) adotada como padrão, embora haja uma tentativa de separação entre o transtorno como é definido (incluindo o desconforto e a insatisfação com o próprio sexo) e a orientação sexual. Trechos do documento, especificamente no que diz respeito aos indícios dos transtornos, agrupados por fases do desenvolvimento, atestam a presença das normatividades reguladoras fundadas na lógica binária do sexo:

Em meninos, a identificação com o gênero oposto é manifestada por uma acentuada preocupação com atividades tradicionalmente femininas. Eles podem manifestar uma preferência por vestir-se com roupas de meninas ou mulheres ou improvisar esses itens a partir de materiais disponíveis, quando os artigos genuínos não estão à sua disposição. [...] Pode ser observada uma preferência particular por brincar de casinha, desenhar meninas bonitas e princesas e assistir televisão ou vídeos de suas personagens femininas favoritas. [...] Esses meninos evitam brincadeiras rudes e esportes competitivos e demonstram pouco interesse por carrinhos ou caminhões ou outros brinquedos não-agressivos, porém estereotipicamente masculinos. Eles podem expressar um desejo de ser meninas e declarar que, quando crescerem, serão mulheres. Pode haver, também, uma insistência em urinar sentados e em fingir que não possuem pênis, escondendo-o entre as pernas (American Psychiatric Association, 1995: 504-505).

Quanto às meninas, o texto continua esclarecendo o que seriam comportamentos típicos:

As meninas com Transtorno da Identidade de Gênero apresentam reaçôes negativas intensas às expectativas ou tentativas dos pais de que se vistam com 
roupas femininas. Algumas podem recusar-se a comparecer à escola ou a eventos sociais em que essas roupas são exigidas. [...] Essas meninas preferem brincar com meninos, e com eles compartilham interesses em esportes de contato, brincadeiras rudes e jogos tradicionalmente masculinos. Elas demonstram pouco interesse em bonecas ou em qualquer forma de roupas ou atividades femininas de faz-de-conta. Uma menina com este transtorno pode recusar-se, ocasionalmente, a urinar sentada. Ela pode afirmar que tem ou terá um pênis e não desejar desenvolver seios ou menstruar. Ela pode declarar que quando crescer será um homem. Essas meninas tipicamente revelam acentuada identificação com o gênero oposto em brincadeiras, sonhos e fantasias (American Psychiatric Association, 1995: 505).

Essa classificação, elaborada pela Associação Americana de Psiquiatria, norteia os profissionais da área da Saúde, incluindo os psicólogos que ainda hoje, nos cursos de graduação em Psicologia, vez por outra, a despeito da resolução do CFP, apresentam aos seus alunos a inclusão da homossexualidade entre as anomalias psicossexuais. A despeito de toda a reivindicação dos movimentos LGBT e do próprio programa recentemente lançado pelo governo brasileiro intitulado "Brasil sem homofobia”, que inclui a preocupação evidente com a área da educação desde o nível básico -, os currículos dos cursos de graduação não contemplam a discussão de gênero e, muito menos, as teorias feministas e queer.

Contudo, pode-se apontar que outra tendência epistemológica surgiu nas últimas décadas, marcando as ciências humanas e sociais, bem como as pesquisas sobre sexualidade desenvolvidas nessas áreas: o chamado construcionismo social, que entende que os fatos humanos não são naturais e sim culturalmente instituídos, em contraposição às interpretações "essencialistas" da sexualidade. No campo da Psicologia, o construcionismo se faz presente, especialmente, entre aqueles que se dedicam às investigações de grupos minoritários. Entende-se, aqui, que os significados sexuais, assim como a experiência ou comportamento sexual, não são passíveis de generalização, uma vez articulados com outras redes de significados e classificações como gerações, gênero e classe (Heilborn \& Brandão, 1999). Gênero, nesse caso, é um dos pontos específicos das discussões sobre o caráter construído da sexualidade e de suas características, embora possa ser tratado como mais abrangente do que a própria sexualidade.

A diferenciação entre sexo e gênero, entretanto, é motivo de debate constante. Também é complicada a distinção entre sexo e sexualidade, sendo esta última, com freqüência, reduzida às práticas sexuais. Para Foucault ([1976] 1997, [1977] 1994), a sexualidade constitui um dispositivo que "fala" a verdade sobre 
o sujeito, é posta como foco das relações de forças empreendidas pelas "ciências humanas", e o sexo seria algo da esfera privada. Se o gênero buscou, como categoria, superar o viés organicista da categoria sexo, por outro lado, as discussões mais recentes que argumentam que o próprio sexo é construído culturalmente colocam em xeque a diferenciação simplista que articula sexo à biologia e gênero à cultura. Igualmente, parece que uma parcela considerável dos estudos de gênero mantém a lógica bipolar, ainda que se utilize de termos como masculino e feminino, parecendo sinônimos de homem e mulher, assim como de um variável sexo, uma vez que a associação entre reprodução e gênero mantém a confusão entre este último, sexo, e sexualidade. Nas perspectivas contemporâneas, são os estudos queer os que mais destacam a separação entre sexualidade reprodutiva e a não-reprodutiva, bem como entre gênero e sexualidade (Rubin, 1984; Vance, 1984; Butler, 2006). Enfatizam a "estratificação sexual" presente nas sociedades modernas que orientaria a inferiorização de indivíduos associados às chamadas práticas sexuais "más”. Catharine MacKinnon (1982), por exemplo, ainda que não trabalhe propriamente com a teoria queer, também considera a sexualidade como uma forma de poder, de sorte que a hierarquia da heterossexualidade institucionaliza a dominação masculina e a submissão feminina e, por conseguinte, o gênero.

Assim como a diferenciação entre sexo e gênero parece complexa e difícil, por outro lado, a articulação entre os dois também não se mostra clara (Vance, 1984; Butler, 2006). Não é por acaso, portanto, que o DSM-IV mantém, no grande item "transtornos sexuais", os chamados "transtornos de identidade de gênero". No entanto, se sexualidade e gênero, em contextos específicos, se interrelacionam, não são fenômenos da mesma ordem. Nas análises sobre sexualidades heterossexuais, via de regra gênero parece aprisionado, como já mencionado, a uma distinção binária clara entre homens e mulheres, ainda que esses trabalhos levem em conta uma série de diferenciações. A entrevista de Gayle Rubin a Judith Butler (2003) mostra a complexidade das distinções entre características consideradas masculinas e femininas quando associadas às práticas sexuais como o sadomasoquismo e o fetichismo, bem como as limitaçôes de tradições teóricas como a psicanalítica, que insiste na idéia das perversōes (Rubin, 1984).

Ademais, o que dizer das situações das cirurgias de transgenitalização e de adequação dos corpos/genitália à binaridade do gênero, hoje defendida até mesmo por muitos médicos, em que sujeitos que adotaram a anatomia do sexo oposto (assim como outros sinais indiciáticos como vestimentas, gestos etc.) mantiveram o desejo/orientação sexual pregressa? Poder-se-ia dizer, então, que existem vários sexos e vários gêneros, implodindo definitivamente o binarismo? 
Para Butler (2006), o gênero é uma norma reguladora que funciona e pune aqueles que dela se desviam, como é o caso da correção cirúrgica de pessoas intersexos, a criminalização e/ou patologização médica-psiquiátrica de pessoas com "transtornos de identidade de gênero" e as discriminaçôes nos vários âmbitos da vida social, tais como no trabalho. Ainda sob o entendimento normativo - como norma -, o gênero é uma forma de poder social que produz o campo de inteligibilidade dos sujeitos e, enquanto tal, emerge como um dispositivo pelo qual a binaridade do gênero é instituída. Embora este binarismo coerente seja contingente, o gênero é o dispositivo pelo qual o masculino e o feminino são produzidos e naturalizados. Todavia, de outro lado, os problemas de gênero, os transgêneros, os cross-gender, dentre outros, sugerem que o gênero pode se deslocar do binarismo naturalizado, de tal sorte que o amálgama de gênero com os binarismos masculino/feminino, homem/mulher, macho/fêmea performa a naturalização que a mesma noção de gênero pode supostamente contra-atacar.

Também é importante destacar que, no mesmo DSM-IV, os transtornos sexuais são apartados das demais perversões, incluindo aqueles relativos ao desejo, à excitação, ao orgasmo e à dor. Entre aqueles considerados como transtornos do desejo sexual, chamam a atenção os que dizem respeito a uma certa "deficiência" da sexualidade: baixo desejo e aversão. Ou seja, parece haver um pressuposto de que a sexualidade normal poderia incluir o excesso de fantasias ou desejo sexual e, com isso, valoriza-se contemporaneamente uma vida sexual ativa. Ademais, aparece o aumento e a busca pela objetivação dos "sintomas", que seriam "expressões polimórficas de processos subjacentes” (Russo, 2004: 108), apontando para a existência de algo que o próprio sujeito desconhece, que o compromete e que demanda um profissional médico capaz de tratar circunscritamente o distúrbio. "O que antes poderia ser interpretado como parte de uma dimensão psicológica não desaparece, mas é transformado e objetificado de modo a poder ser descrito, interpretado e tratado medicamente", de acordo com Jane Russo (2004: 108) inspirada em Foucault. O que aponta, segundo a mesma autora, para a objetificação e fragmentação do próprio sujeito.

Além disso, é importante destacar que o diagnóstico dos Transtornos de Identidade de Gênero, conforme proposição do $D S M-I V$, requer um sentimento de inadequação, um desconforto com relação ao gênero, o que permite supor que as normas de gênero são fixas e que a questão é seguir a "boa norma" para que se possa encontrar o lugar adequado, sentir-se bem com o próprio gênero (gênero próprio) (Butler, 2006).

Para finalizar, gostaria de retomar a complexa significação da sexualidade humana, haja vista a diversidade de tendências teórico-epistemológicas e ideoló- 
gicas que caracterizam as discussões em torno do tema. A heteronormatividade impera ainda nos dias atuais como um padrão que estende suas implicações desde o cotidiano da vida dos sujeitos até os estudos e concepções sobre a normalidade e as anomalias nesse cenário, mesmo porque os saberes "científicos" produzem seus conhecimentos a partir da observação e classificação das práticas rotineiras. Assim, as terminologias mudam (gays, lésbicas, travestis, transgêneros, drags, intersex, etc.), mas as regras morais associadas às explicações científicas parecem perdurar, compreendendo a sexualidade de forma naturalizada e perigosa. $\mathrm{O}$ fetichismo, o travestismo e o sadomasoquismo, por exemplo, continuam presentes como transtornos tanto no DSM-IV, quanto no CID-10 (World Health Organization, 2005), assim como os transtornos da identidade de gênero. Nesse caso, pode-se argumentar que o caráter polimórfico da sexualidade humana não é visto como "normal", a despeito de todas as lutas nesse sentido.

Butler (1990) afirma que a matriz heterossexual, como regime epistemológico produtor e reificador de categorias ontológicas, conforma a binariedade homensmulheres para a conceituação do gênero e do desejo. É a heterossexualidade compulsória que exige a coerência e a continuidade entre sexo-gênero-prática sexualdesejo, de sorte a constituir gêneros inteligíveis. Essa matriz exige que certos tipos de "identidade" não possam "existir" (aquelas em que o gênero não decorre do sexo e aquelas em que as práticas do desejo não decorrem nem do sexo, nem do gênero, como nos casos mencionados acima). Nesses casos, os chamados "transtornos de identidade de gênero" não seriam impossibilidades lógicas por não se conformarem às normas da inteligibilidade cultural e não "falhas do desenvolvimento" como querem levar a crer os discursos médicos e psicológicos? Se considerarmos que as categorias psicológicas (ego, indivíduo, pessoa, identidade) são produtos da realidade lingüística, que a identidade não passa de uma ficção reguladora e que o gênero designa, qualifica, universaliza o binarismo por meio de uma episteme conceitual, não há um sexo a priori, uma natureza que se desvia em seu desenvolvimento. Há regimes diferentes de poder que produzem os conceitos de identidade sexual e a correspondente relação mimética entre gênero e sexo (o primeiro refletindo o segundo ou sendo restrito por ele) (Butler, 1990).

A despeito de toda essa discussão e das manifestações da Associação Americana de Psicologia, da Associação Americana de Psiquiatria e da Sociedade Interamericana de Psicologia, em maio de 2008 foi realizado na cidade do México um congresso denominado "Compreendendo a homossexualidade", promovido pela organização "Renascer", com a finalidade de promover o "tratamento" da homossexualidade, por ela denominada "atração pelo mesmo sexo" (AMS). Convidados estadunidenses e latino-americanos, fortemente ligados a grupos cristãos, defen- 
deram a idéia da "reorientação" de pessoas com AMS mediante terapia, tal como preconizada pela organização privada National Association for Research and Therapy of Homosexuality (NARTH), dos Estados Unidos da América. A participação das religiōes nesse campo é mais do que evidente. Ela se manifesta também junto aos governos e às organizaçôes internacionais como a ONU, configurando um forte lobby que dificulta os acordos relativos aos direitos sexuais e o combate a qualquer forma de discriminação relativa à orientação sexual.

\section{DiREITOS SEXUAIS COMO DIREITOS HUMANOS}

No cenário das discussões internacionais sobre os direitos sexuais, ganha destaque a Conferência Internacional sobre População e Desenvolvimento, realizada no Cairo, em 1994, por ter proposto a superação da perspectiva de saúde reprodutiva que enfatiza o controle da natalidade, além de ter reconhecido a sexualidade enquanto uma esfera positiva da atuação humana (Barzelatto, 1998) que inclui sexo, identidades e papéis de gênero, orientação sexual, erotismo, prazer, intimidade e reprodução. Segundo a definição adotada pela Organização Mundial de Saúde (World Health Organization, 2008), os direitos sexuais seguem os direitos humanos que já são reconhecidos pelas leis e documentos internacionais consensuais. Eles incluem o direito de todas as pessoas e repudiam qualquer forma de coerção, discriminação ou violência, devendo ser protegidos e respeitados.

Durante o XV Congresso Mundial de Sexologia, ocorrido em Hong Kong (China), entre 23 e 27 de agosto de 2000, a Assembléia Geral da WAS - World Association for Sexology, aprovou as emendas para a Declaração de Direitos Sexuais, decidida em Valência, no XIII Congresso Mundial de Sexologia, em 1997. Dentre eles, encontra-se o direito à liberdade sexual, entendida como a "liberdade de todas as formas de amar sem discriminação, independentemente do sexo, gênero, orientação sexual, idade, raça, classe social, religião, deficiências mentais ou físicas" (World Association for Sexology, 2008: s/p). A Declaração afirma o entendimento de que os direitos sexuais são direitos humanos universais baseados na liberdade inerente, dignidade e igualdade para todos os seres humanos, e que "devem ser reconhecidos, promovidos, respeitados e defendidos por todas sociedades de todas as maneiras" (World Association for Sexology, 2008: s/p).

No ano de 2003 a diplomacia brasileira apresentou a proposta de Resolução intitulada "Direitos Humanos e Orientação Sexual" na 59a Reunião da Comissão de Direitos Humanos na ONU. A Resolução foi vista com entusiasmo pelos movimentos que trabalham com direitos sexuais e direitos humanos. No entanto, muçulmanos e católicos uniram-se, impedindo que a resolução fosse aprovada. $\mathrm{O}$ Governo brasileiro, em função de acordos econômicos com os países árabes, se- 
quer apresentou a proposta este ano. Esta Resolução tem uma importância enorme, pois tira da clandestinidade lésbicas, gays, transgêneros e intersexo, que vivem situação de constrangimento e discriminação em função da sua orientação sexual e muitas vezes, como é o caso dos países árabes, são submetidos a leis punitivas, que os leva à cadeia, tortura e, não raro, à morte.

A despeito das discussões teórico-conceituais, dos entendimentos das associações científicas e dos esforços das organizações políticas internacionais, os direitos sexuais não são assegurados como propostos pela Declaração aprovada pela WAS. A influência das religiões nesse cenário é evidente. Não se restringindo à diversidade sexual, pode-se identificar o discurso religioso atuante em questôes como a da descriminalização do aborto e a das pesquisas com células tronco, conforme testemunhamos no Brasil recentemente. No último caso, por exemplo, temos a decisão do Supremo Tribunal Federal, com o parecer do Ministro Carlos Ayres de Britto, que explicita a diferenciação entre questões de Estado e questôes de ordem religiosa ou foro pessoal. $\mathrm{O}$ argumento do "respeito à vida" nesses casos confunde-se com os enunciados moralizantes que se imiscuem em questóes de Estado que, por sua vez, deveria ser assegurado como laico. Observa-se aqui a assunção novamente do biopoder, associado aos discursos religiosos e a processos de criminalização, de forma a assegurar o controle sobre a vida dos indivíduos e o cerceamento do exercício autônomo da sexualidade.

Deixo algumas questões para a continuidade do debate:

1) Quais são os limites e as possibilidades da defesa do caráter polimórfico da sexualidade humana e suas implicações ético-políticas, por exemplo, no debate sobre a prostituição e a pedofilia?

2) Como "desfazer o gênero" no sentido de seu binarismo?

Podemos identificar de fato um deslocamento nas classificações dos transtornos mentais e da sexualidade na direção da biomedicina, como defende Russo (2004)? Ou eles sempre estiveram, de alguma maneira na modernidade, nela ancorados?

\section{REFERÊNCIAS BIBLIOGRÁFICAS}

American Psychiatric Association. (1995). DSM IV - Manual diagnóstico e estatístico de transtornos mentais. Porto Alegre: Artes Médicas.

Barzelatto, J. (1998). Desde el control de la natalidad hacia la salud sexual y reproductiva: la evolución de un concepto a nivel internacional. Em Bilac, E. D. \& Rocha, M. I. B. (Orgs.). Saúde reprodutiva na América Latina e no Caribe: temas e problemas (pp. 3949). Campinas: PROLAB, ABEP, NEPO, UNICAMP. 
Butler, J. (1990). Gender Trouble. Feminism and the subversion of identity. New York: Routlegde.

- (2003). O parentesco é sempre tido como heterossexual? Cadernos Pagu, 21, $219-260$.

. (2006). Défaire le genre. Paris: Éditions Amsterdam.

Conselho Federal de Psicologia. (1999). Resolução 01/1999.

Derrida, J. (1994). Lectures de la différence sexuelle. Paris: Édition des Femmes.

Duarte, L. F. D. (2004). A sexualidade nas Ciências Sociais: leitura crítica das convenções.

Em Piscitelli, A.; Gregori, M. F. \& Carrara, S. (Orgs.). Sexualidades e saberes: convençôes e fronteiras (pp. 39-80). Rio de Janeiro: Garamond.

Foucault, M. (1976). História da sexualidade I: a vontade de saber. Rio de Janeiro: Graal, 1997.

. (1977). Le Jeu de Michel Foucault. Em Dits et écrits: 1954-1988, vol. III (pp. 298-329). Paris: Gallimard, 1994.

Heilborn, M. L. \& Brandão, E. R. (1999). Introdução: ciências sociais e sexualidade. Em Heilborn, M. L. (org.). Sexualidade. O olhar das ciências sociais (pp. 7-17). Rio de Janeiro: Zahar.

Laqueur, T. (1992). Sexo, corpo e gênero dos gregos a Freud. Rio de Janeiro: Relume-Dumará. Loyola, M. A. (Org.). (1998). A sexualidade nas ciências humanas. Rio de Janeiro: Editora UERJ.

Mackinnon, C. (1982). Marxism, feminism and the State: toward feminist jurisprudence. Signs: Journal of women in culture and society, 7, 515-44.

Piscitelli, A.; Gregori, M. F. \& Carrara, S. (Orgs.). (2004). Sexualidades e saberes: convençôes e fronteiras. Rio de Janeiro: Garamond.

Rubin, G. (1984). Thinking sex: notes for a radical theory of the politics of sexuality. Em Vance, C. (Org.). Pleasure and danger: exploring female sexuality (pp. 267-319). Boston: Routledge \& Kegan Paul.

Rubin, G. \& Butler, J. (2003). Tráfico sexual: entrevista. Cadernos Pagu, 21, 157-209.

Russo, J. A. (2004). Do desvio ao transtorno: a medicalização da sexualidade na nosografia psiquiátrica contemporânea. Em Piscitelli, A.; Gregori, M. F. \& Carrara, S. (Orgs.). Sexualidades e saberes: convençôes e fronteiras (pp. 95-114). Rio de Janeiro: Garamond. Vance, C. (ed.). (1984). Pleasure and danger: exploring female sexuality. Boston: Routledge \& Kegan Paul.

World Association for Sexology. (2008). Universal Declaration of Sexual Rights. Disponível em <http://www.tc.umn.edu/ - colem001/was/wdeclara.htm>. Acessado em 07 de outubro de 2008. 
World Health Organization. (2005). Décima revisão da Classificação Internacional de Doenças - CID 10. Disponível em <http://www.who.int/classifications/icd/en/index.html>. Acessado em 07 de outubro de 2008.

World Health Organization. (2008). Glossário. Disponível em <http://www.who.int/ reproductive-health/gender/glossary.html>. Acessado em 07 de outubro de 2008.

\section{NoTAS}

1 I Encontro Interdisciplinar em Sexualidade, realizado em agosto de 2005, na Universidade Federal de Santa Catarina (UFSC) e organizado pela Associação Brasileira de Obstetrizes e Enfermeiros Obstetras (ABENFO/SC).

2 Seminário Internacional Fazendo Gênero 7: Gênero e Preconceitos, realizado na Universidade Federal de Santa Catarina (UFSC), em agosto de 2006.

Recebido em 24 de março de 2008 Aceito para publicação em 09 de outubro de 2008 